OPEN ACCESS

Edited by:

Tania Zaglia,

University of Padova, Italy

Reviewed by:

Nazareno Paolocci,

Johns Hopkins University,

United States

Matthew W. Kay,

George Washington University,

United States

Michael Rubart,

Indiana University Bloomington,

United States

*Correspondence:

Beth A. Habecker

habecker@ohsu.edu

Specialty section:

This article was submitted to Hypertension,

a section of the journa

Frontiers in Cardiovascular Medicine

Received: 24 December 2021

Accepted: 19 January 2022

Published: 10 February 2022

Citation:

Clyburn C, Andresen MC, Ingram SL and Habecker BA (2022) Untangling Peripheral Sympathetic Neurocircuits.

Front. Cardiovasc. Med. 9:842656.

doi: 10.3389/fcvm.2022.842656

\section{Untangling Peripheral Sympathetic Neurocircuits}

\author{
Courtney Clyburn ${ }^{1}$, Michael C. Andresen ${ }^{1}$, Susan L. Ingram ${ }^{2}$ and Beth A. Habecker ${ }^{1 *}$ \\ ${ }^{1}$ Department of Chemical Physiology and Biochemistry, Oregon Health and Science University, Portland, OR, United States, \\ ${ }^{2}$ Department of Neurological Surgery, Oregon Health and Science University, Portland, OR, United States
}

The sympathetic nervous system plays a critical role in regulating many autonomic functions, including cardiac rhythm. The postganglionic neurons in the sympathetic chain ganglia are essential components that relay sympathetic signals to target tissues and disruption of their activity leads to poor health outcomes. Despite this importance, the neurocircuitry within sympathetic ganglia is poorly understood. Canonically, postganglionic sympathetic neurons are thought to simply be activated by monosynaptic inputs from preganglionic cholinergic neurons of the intermediolateral cell columns of the spinal cord. Early electrophysiological studies of sympathetic ganglia where the peripheral nerve trunks were electrically stimulated identified excitatory cholinergic synaptic events in addition to retrograde action potentials, leading some to speculate that excitatory collateral projections are present. However, this seemed unlikely since sympathetic postganglionic neurons were known to synthesize and release norepinephrine and expression of dual neurochemical phenotypes had not been well recognized. In vitro studies clearly established the capacity of cultured sympathetic neurons to express and release acetylcholine and norepinephrine throughout development and even in pathophysiological conditions. Given this insight, we believe that the canonical view of ganglionic transmission needs to be reevaluated and may provide a mechanistic understanding of autonomic imbalance in disease. Further studies likely will require genetic models manipulating neurochemical phenotypes within sympathetic ganglia to resolve the function of cholinergic collateral projections between postganglionic neurons. In this perspective article, we will discuss the evidence for collateral projections in sympathetic ganglia, determine if current laboratory techniques could address these questions, and discuss potential obstacles and caveats.

\section{Keywords: sympathetic ganglia, neurocircuits, synaptic inputs, co-transmission, collaterals}

\section{INTRODUCTION}

Technical advances have long driven new insights into the mechanistic basis of neurophysiology. From the identification of the action potential in the nineteenth century (1) to the work of Joseph Erlanger and Herbert Gasser who revolutionized neurophysiological research by developing sensitive oscilloscopes that allowed for the visualization and analysis of nerve impulses previously below the threshold of detection $(2,3)$. With these technological advancements, researchers set out to decode the complex autonomic signals that regulate visceral functions, including cardiac 
activity (4-6). Several important hypotheses arose from this work, but were untested due to experimental limitations that existed at the time. These questions include whether or not collateral projections are present between postganglionic neurons in sympathetic ganglia and what neurotransmitters may be involved in sympathetic signaling pathways. Since these first studies, significant advancements in neurophysiological equipment and scientific methods have allowed for substantial progress in understanding the neurophysiology of peripheral sympathetic activity (7-11), but the neurocircuitry within sympathetic ganglia remains poorly understood. The purpose of this article is to review the primary data that support these untested hypotheses, determine if current technology and experimental methods can be used to answer these important questions, and discuss any potential obstacles that may arise.

\section{Canonical Neurocircuitry of Cervical Sympathetic Ganglia}

Several well-written review articles are available that thoroughly summarize our current understanding of the sympathetic neurocircuitry that regulates visceral functions and cardiac activity (12-16). To briefly summarize, sympathetic signals originate in the hypothalamus and brainstem and travel to the preganglionic neurons in the intermediolateral cell column of the spinal cord. These preganglionic neurons send cholinergic projections to postganglionic neurons in the cervical sympathetic chain ganglia. These neurons in the sympathetic ganglia then send noradrenergic projections through the postganglionic nerve trunk to innervate the target tissue. This general organization is conserved across species. However, there is significant biological variability in the anatomy and physiology of the cervical sympathetic ganglia which clouds our understanding of peripheral sympathetic neurocircuits. The cervical sympathetic chain includes the superior, middle, and inferior cervical ganglia and exhibits significant anatomical variability between species, between individuals, and even between the left and right ganglia. In approximately $80 \%$ of humans, for example, the inferior cervical ganglion is fused with the first thoracic ganglion to form the cervicothoracic (commonly known as stellate) ganglion. Additionally, the middle cervical ganglion is completely absent in $\sim 20 \%$ of the population (17-20). In considering the variability in the sympathetic nervous system in humans and animal models as well as the murkiness that surrounds the functional organization of the cervical sympathetic ganglia, we will consider data from all cervical sympathetic ganglia interchangeably as we discuss peripheral sympathetic neurocircuitry.

\section{Evidence for Collateral Projections in Sympathetic Ganglia}

In addition to the ambiguity surrounding the anatomy of the sympathetic ganglia, the functional organization of the sympathetic neurocircuitry within these ganglia remains poorly defined. Current literature usually describes and illustrates the neurocircuitry within cervical sympathetic ganglia as simple monosynaptic connections from cholinergic preganglionic neurons to the noradrenergic postganglionic neurons that innervate visceral targets and the heart $(21,22)$. However, Erulkar and Woodward (23) made intracellular recordings of postganglionic sympathetic neurons from rabbit superior cervical ganglia (SCG) in situ which suggest this neurocircuitry may be more complicated. In these early experiments, they found that stimulation of the external carotid nerve produced single, short latency spikes followed by long-lasting hyperpolarizations (presumably action potentials) in some neurons. In these experiments, electrical stimulation of the postganglionic nerve trunk evoked antidromic, or retrograde, action potentials that traveled up the axon to the cell body in the SCG. Surprisingly, the majority of neurons exhibited an early spike followed by a long-lasting depolarization. This depolarization suggested that stimulation of the postganglionic nerve trunk elicited excitatory synaptic activity within the SCG. Erulkar and Woodward proposed several hypotheses that would account for this phenomenon, but state that the simplest explanation would be that recurrent excitatory collateral fibers from postganglionic axons project to neighboring cells within the SCG (Figure 1). Upon stimulation of the preganglionic nerve trunk, Erulkar and Woodward also observed that a significant proportion of SCG neurons exhibited multi-spike responses which were uncovered at increasing stimulation intensities. While they acknowledge these results may be caused by different populations of preganglionic fibers with different thresholds and conduction velocities that converge onto the same cell, this explanation seems highly unlikely. Instead, they note that the multi-spike responses are consistent with the collateral hypothesis and that the late-arriving impulses may have traveled through another indirect pathway.

Excitatory synaptic events in postganglionic sympathetic neurons following electrical stimulation of the postganglionic nerve trunk have also been observed in the cat, rat and guinea pig (24-26). In 1970, Perri et al. extended the observations by Erulkar and Woodward by investigating the neurotransmitter that may be involved in these synaptic events. Curare, a nicotinic acetylcholine (ACh) receptor antagonist, applied to the ganglionic preparation abolished these synaptic events, indicating they were likely cholinergic in nature (25). If these excitatory events originated from postganglionic collateral projections, this would mean that these sympathetic neurons express ACh and norepinephrine (NE). Although we now know that postganglionic sympathetic neurons and other neurons can express a dual neurochemical phenotype (27-31), at the time this was thought to be unlikely. Thus, researchers sought alternative explanations. These included the possibility that errant preganglionic fibers may be running up the postganglionic nerve trunk and forming excitatory synaptic connections with postganglionic neurons (Figure 1) (25). A second possibility raised was that sensory afferent neurons were the source of synaptic excitation. Sympathetic ganglia have long been linked to sensory afferents of the cardiac region of the thoracic viscera (6) but on the bases of such anatomical findings broadly dismissed as only passing through the ganglia on their way to the spinal cord. Thus, sketches commonly depict that a portion of these afferent paths include sympathetic ganglia 


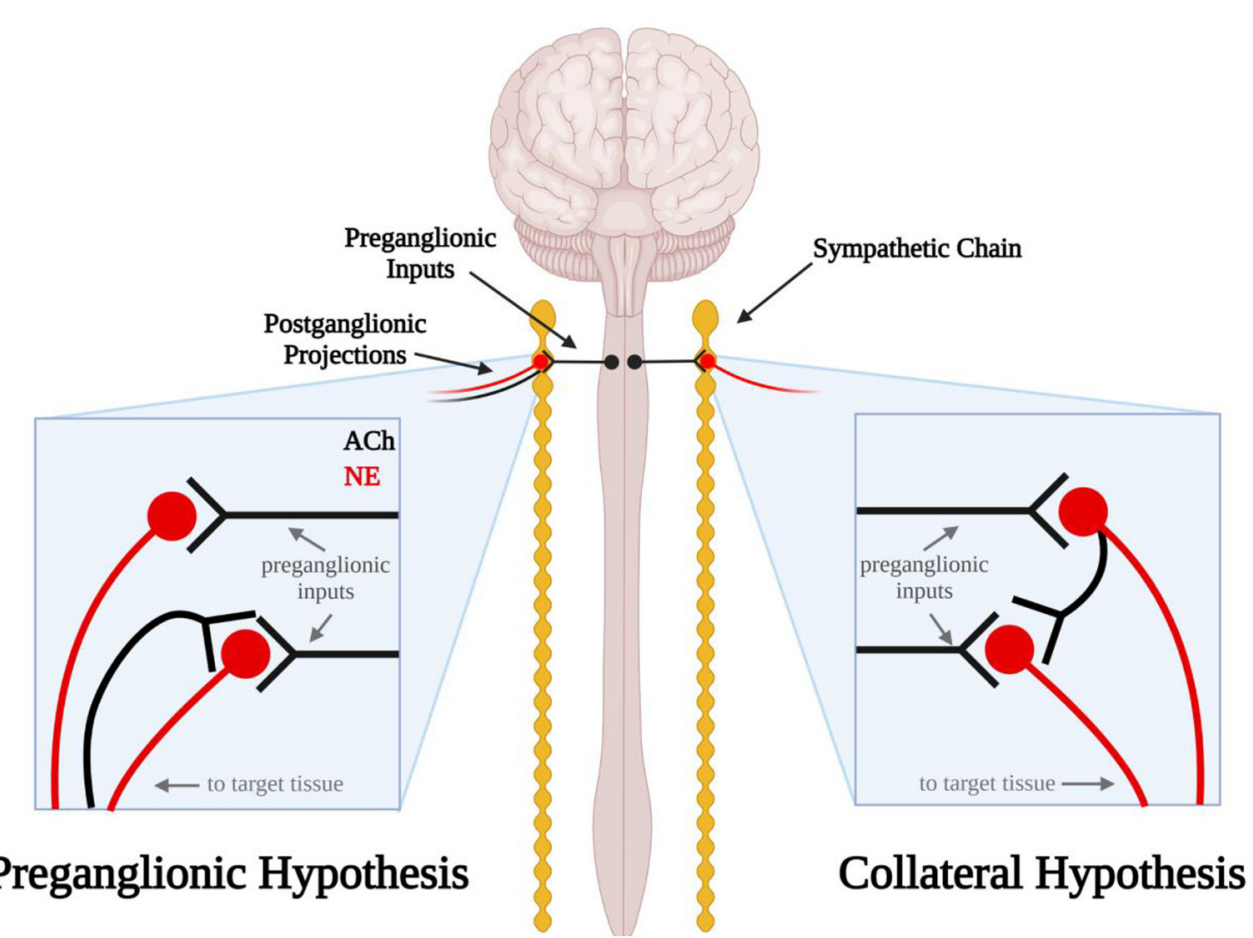

FIGURE 1 | Schematic diagram illustrating the errant preganglionic fiber and collateral hypotheses. In the preganglionic hypothesis (left), mis-routed cholinergic (black) preganglionic fibers travel back up the efferent nerves through which sympathetic axons travel to the target tissue. In the collateral hypothesis (right) postganglionic sympathetic neurons send noradrenergic projections (red) to the target tissue and cholinergic projections (black) to other sympathetic neurons in the sympathetic chain ganglia.

(e.g., cervical and stellate) (32). However, functional studies related to cardiovascular regulation, for example, indicate that activation of cardiac sensory afferents traveling via the stellate ganglia act to increase blood pressure by augmenting sympathetic motor neuron activity directed to the systemic vasculature and such responses are abolished by severing ganglion connections to the spinal cord (33). Dye tracing and electrical activity recordings indicate that such afferent neurons arise from the dorsal root ganglia and traverse peripheral sympathetic ganglia to their visceral targets (34). Although it seemed unlikely at the time, our current understanding of dual neurochemical phenotypes in sympathetic neurons has persuaded us that further studies are needed to investigate the potential presence of cholinergic collateral projections between postganglionic neurons in sympathetic ganglia.

\section{Evidence for Dual Neurochemical Phenotypes in Sympathetic Neurons}

In 1935, Henry Dale put forth the "one neuron, one neurotransmitter" hypothesis which was later termed as "Dale's Principle" $(35,36)$ and stated that one neuron was only capable of releasing one neurotransmitter at any one time [reviewed by: (37)]. By the mid-1970s, evidence disputing Dale's Principle began to emerge when Jan and colleagues made intracellular recordings of sympathetic frog neurons and observed slow synaptic potentials which were mediated by the peptide, luteinizing hormone-releasing hormone, in addition to the canonical cholinergic transmission $(38,39)$. Since these initial studies, co-transmission of several neuromodulators, including ATP and neuropeptide Y (NPY) (40-44), as well as the cotransmission of fast primary neurotransmitters have been well established throughout the central and peripheral nervous system (45-47).

Some of the earliest evidence supporting co-expression of primary neurotransmitters comes from cardiac myocytesympathetic neuron co-cultures (48). In 1976, Furshpan et al. used electrophysiological recordings of sympathetic SCG principal neurons cultured with cardiac myocytes from newborn rats and described a population of neurons that secreted ACh and NE (48-51). This work sparked a series of studies to determine if sympathetic neurons produced $\mathrm{ACh}$ in vivo and to identify the differentiation factors that determine the fates of sympathetic neurons (52). Several "cholinergic differentiation factors" are now known to induce ACh expression in noradrenergic sympathetic neurons including leukemia inhibitor factor (LIF), ciliary neurotrophic factor (CNTF), cardiotrophin-1 (CT-1), neurotrophin-3 (NT-3) and glial cell line-derived neurotrophic factor (GDNF) (53-61). While the cholinergic transdifferentiation of postganglionic sympathetic neurons in vivo was first thought to be confined to developmental periods, more recent studies have shown that inflammatory cytokines can induce cholinergic transdifferentiation in cardiac 
disease $(30,62)$. Early studies have revealed key aspects of the neurochemical phenotype of sympathetic neurons: dual and malleable neurochemical capacity. These studies of cultured neurons indicated that these postganglionic neurons could form synapses between neurons and could display adrenergic/cholinergic dual function (50). In culture, the neurotrophin brain-derived neurotrophic factor (BDNF) rapidly shifted sympathetic neuron release of norepinephrine to $\mathrm{ACh}$ indicating the dual neurochemical phenotype of these postganglionic neurons (31). Subsequent work also in cultured neurons supported both segregation as well as plasticity of functional release sites of $\mathrm{NE}$ and $\mathrm{ACh}$ (63). In light of this evidence, it appears that the cholinergic hypothesis originally proposed by Erulkar and Woodward in 1968 was dismissed prematurely before fully testing the idea. Gaining a clear insight into the neurocircuitry within sympathetic ganglia can provide better understanding of the mechanisms underlying autonomic imbalance in disease and may highlight novel therapeutic targets for cardiac patients.

\section{Challenges and Potential Caveats}

The dual expression of $\mathrm{ACh}$ and $\mathrm{NE}$ in sympathetic neurons provides support for the collateral hypothesis, but there are still many questions that remain. When dual neurochemical phenotypes were first described, these neurons were generally classified into two mechanistic subtypes, co-release and cotransmission $(37,64)$. Co-release describes the packaging of multiple neurotransmitters into the same synaptic vesicle so they there are released together and co-transmission originally described different neurotransmitters packaged into different vesicles within the same presynaptic terminal $(37,64)$. Dale's Principle was updated in 1986 to state that neurons release the same group of neurotransmitters/peptides from all presynaptic terminals $(64,65)$. However, the collateral hypothesis challenges this view because the primary data indicates that $\mathrm{ACh}$ is released from the collateral terminals. The excitatory synaptic events that are observed following stimulation of the postganglionic nerve trunk are completely blocked by the application of nicotinic acetylcholine antagonists $(24,25)$. In the collateral model, this could suggest the biased expression of ACh and NE at different synapses within the same neuron. Based on the updated version of Dale's hypothesis, we would expect that both ACh and NE would be released from collateral synapses. As adrenergic receptors are G-protein coupled receptors, synaptic release of NE cannot be detected with the electrophysiological techniques used in these previous studies (25). Future experiments could utilize new biosensor technology to determine if $\mathrm{NE}$ is also released from collateral projections (66-68). If $\mathrm{NE}$ is not released from collateral projections, there are several mechanisms that have been described in the CNS that could explain biased release of different vesicular pools. These include differing release probabilities and altered coupling to presynaptic $\mathrm{Ca}^{2+}$ channels $(69,70)$, "kiss-and-run" release mechanisms, and even neurotransmitter segregation to separate axons $(64,71-74)$. Studies in cultured sympathetic neurons have observed segregation of the vesicular NE and ACh transporters
(VMAT2 and VAChT, respectively) in distinct varicosities, suggesting release of each transmitter is independent and spatially segregated (63). Considering how target-derived factors and cytokines can induce cholinergic transdifferentiation in postganglionic sympathetic neurons, it is conceivable that factors in the microenvironment are involved in determining different neurochemical identities of synaptic terminals in the ganglia and target tissues.

Putative afferent fibers could have an important physiological role in allowing sensory feedback to regulate the activity of postganglionic sympathetic neurons in the event that inputs from the central nervous system are disrupted. This sensory feedback loop would also allow for the fast adaptation of sympathetic neuron activity to rapidly changing stimuli (24). However, the synaptic events that are observed following stimulation of the postganglionic nerve trunk are mediated by acetylcholine and, therefore, unlikely to be mediated by sensory fibers, which utilize glutamatergic signaling. The physiological consequence of putative cholinergic collateral projections is less obvious. Collateral projections between postganglionic sympathetic neurons may also have a significant physiological role in maintaining autonomic control of the heart and other tissues. Excitatory collateral projections between postganglionic sympathetic neurons would increase the probability that these neurons fire synchronously and may amplify preganglionic signals from the spinal cord. Given the importance of neural timing for cardiopulmonary integration, the synchronization of sympathetic inputs could potentially play a critical role in maintaining appropriate cardiac activity. Furthermore, disruption of this synchronization following injury or disease could exacerbate autonomic imbalance. Early studies hypothesized that single spikes in recordings of cardiac sympathetic nerve activity represent synchronized activity of multiple postganglionic neurons (75), but the potential role of collateral synapses in this synchronization is purely speculative.

It was not possible in the past to distinguish preganglionic cholinergic transmission from putative post-ganglionic collateral projections, but transgenic mouse models and genetic tools provide the means to address this issue now. Targeted deletion of ACh production (chat gene) or release (slc18A3 gene) from neurons expressing tyrosine hydroxylase (th gene), dopamine beta hydroxylase ( $d b h$ gene), or norepinephrine transporter (slc6a2 gene) would remove cholinergic transmission selectively from post-ganglionic neurons within the ganglion. Likewise, targeting expression of channelrhodopsin-2 or other stimulatory optogenetic tools to noradrenergic neurons would allow selective stimulation of those cells, coupled with recordings of resulting synaptic activity. Combining these approaches with the use of genetically encoded calcium sensors would allow testing the functional impact of putative cholinergic collateral transmission in situ. Mouse lines to facilitate these studies, which directly address the issue of potential cholinergic collaterals, are available from public repositories. If cholinergic collaterals are an important aspect of transmission by post-ganglionic sympathetic neurons then we would expect them to be present and detectable throughout 
the sympathetic chain, and lead to changes in transmission to target tissues.

\section{DISCUSSION}

While some of the first studies investigating sympathetic nerve impulses proposed that collateral projections may be present in the sympathetic ganglia, this model was dismissed because of our incomplete understanding of dual neurochemical phenotypes. In hindsight, given our understanding of cotransmission of $\mathrm{ACh}$ and $\mathrm{NE}$ in postganglionic sympathetic neurons, it is clear that studies should be carried out to clarify the neurocircuitry within the sympathetic ganglia. The postganglionic neurons within sympathetic ganglia are critical components of the neurocircuitry responsible for relaying autonomic signals from the central nervous system to several visceral targets, including the heart. The activity of postganglionic sympathetic neurons is disrupted in many pathologies and sympathetic hyperactivity elevates risk for cardiac arrhythmias and sudden cardiac death and contributes to the development of heart failure. A detailed understanding sympathetic neurocircuitry is needed to understand how peripheral sympathetic activity is disrupted in pathophysiological conditions and to develop novel therapeutic strategies.

\section{REFERENCES}

1. Schuetze SM. The discovery of the action potential. Trends Neurosci. (1983) 6:164-8. doi: 10.1016/0166-2236(83)90078-4

2. Erlanger J, Bishop G, Gasser H. Experimental analysis of the simple action potential wave in nerve by the cathode ray oscillograph. Am J Physiol Legacy Content. (1926) 78:537-73. doi: 10.1152/ajplegacy.1926.78.3.537

3. Erlanger J, Gasser H. The action potential in fibers of slow conduction in spinal roots and somatic nerves. Am J Physiol. (1930) 92:4382. doi: 10.1152/ajplegacy.1930.92.1.43

4. Adrian ED, Bronk DW, Phillips G. Discharges in mammalian sympathetic nerves. J Physiol. (1932) 74:115-33. doi: 10.1113/jphysiol.1932.sp002 832

5. Langley JN. On axon-reflexes in the pre-ganglionic fibres of the sympathetic system. J Physiol. (1900) 25:364-98. doi: 10.1113/jphysiol.1900.sp000803

6. Ranson S, Billingsley P. The superior cervical ganglion and the cervical portion of the sympathetic trunk. J Comp Neurol. (1918) 29:313358. doi: 10.1002/cne.900290403

7. Briant LJ, Paton JF, Pickering AE, Champneys AR. Modelling the vascular response to sympathetic postganglionic nerve activity. J Theor Biol. (2015) 371:102-16. doi: 10.1016/j.jtbi.2015.01.037

8. Carter JR. Microneurography and sympathetic nerve activity: a decadeby-decade journey across 50 years. J Neurophysiol. (2019) 121:118394. doi: 10.1152/jn.00570.2018

9. Greaney JL, Kenney WL. Measuring and quantifying skin sympathetic nervous system activity in humans. J Neurophysiol. (2017) 118:218193. doi: 10.1152/jn.00283.2017

10. Hart EC, Head GA, Carter JR, Wallin BG, May CN, Hamza SM, et al. Recording sympathetic nerve activity in conscious humans and other mammals: guidelines and the road to standardization. Am J Physiol Heart Circ Physiol. (2017) 312:H1031-51. doi: 10.1152/ajpheart.00703.2016

11. Macefield VG. Sympathetic microneurography. Handb Clin Neurol. (2013) 117:353-64. doi: 10.1016/B978-0-444-53491-0.00028-6

12. Dampney RA. Central neural control of the cardiovascular system: current perspectives. Adv Physiol Educ. (2016) 40:28396. doi: 10.1152/advan.00027.2016

\section{DATA AVAILABILITY STATEMENT}

The original contributions presented in the study are included in the article, further inquiries can be directed to the corresponding author.

\section{AUTHOR CONTRIBUTIONS}

CC, MA, SI, and BH contributed to drafting the work and revising it critically for important intellectual content. All authors approved the final version of the manuscript and agree to be accountable for all aspects of the work. All persons designated as authors qualify for authorship, and all those who qualify for authorship are listed.

\section{FUNDING}

This work was supported by the National Institutes of Health Grant HL146833.

\section{ACKNOWLEDGMENTS}

The figure in this article was created with BioRender.com.

13. Fukuda K, Kanazawa H, Aizawa Y, Ardell JL, Shivkumar K. Cardiac innervation and sudden cardiac death. Circ Res. (2015) 116:200519. doi: 10.1161/CIRCRESAHA.116.304679

14. Habecker BA, Anderson ME, Birren SJ, Fukuda K, Herring N, Hoover DB, et al. Molecular and cellular neurocardiology: development, and cellular and molecular adaptations to heart disease. J Physiol. (2016) 594:385375. doi: 10.1113/JP271840

15. Rajendran PS, Challis RC, Fowlkes CC, Hanna P, Tompkins JD, Jordan $\mathrm{MC}$, et al. Identification of peripheral neural circuits that regulate heart rate using optogenetic and viral vector strategies. Nat Commun. (2019) 10:1944. doi: 10.1038/s41467-019-09770-1

16. Scalco A, Moro N, Mongillo M, Zaglia T. Neurohumoral cardiac regulation: optogenetics gets into the groove. Front Physiol. (2021) 12:726895. doi: 10.3389/fphys.2021.726895

17. Fazliogullari Z, Kilic C, Karabulut AK, Yazar F. A morphometric analysis of the superior cervical ganglion and its surrounding structures. Surg Radiol Anat. (2016) 38:299-302. doi: 10.1007/s00276-0151551-3

18. Narouze S. Ultrasound-guided stellate ganglion block: safety and efficacy. Curr Pain Headache Rep. (2014) 18:424. doi: 10.1007/s11916-014-0424-5

19. Pather N, Partab P, Singh B, Satyapal KS. The sympathetic contributions to the cardiac plexus. Surg Radiol Anat. (2003) 25:210-5. doi: 10.1007/s00276-003-0113-2

20. Yin Z, Yin J, Cai J, Sui T, Cao X. Neuroanatomy and clinical analysis of the cervical sympathetic trunk and longus colli. J Biomed Res. (2015) 29:501-7. doi: 10.7555/JBR.29.20150047

21. Jänig W. Organization of the sympathetic nervous system: peripheral and central aspects. Neuroimmune Biol. (2008) 7:55-85. doi: 10.1016/S1567-7443(07)00204-9

22. Vegh AMD, Duim SN, Smits AM, Poelmann RE, Ten Harkel ADJ, DeRuiter $\mathrm{MC}$, et al. Part and parcel of the cardiac autonomic nerve system: unravelling its cellular building blocks during development. J Cardiovasc Dev Dis. (2016) 3:28. doi: $10.3390 /$ jcdd 3030028

23. Erulkar SD, Woodward JK. Intracellular recording from mammalian superior cervical ganglion in situ. J Physiol. (1968) 199:189203. doi: $10.1113 /$ jphysiol.1968.sp008648 
24. Bosnjak ZJ, Kampine JP. Cardiac sympathetic afferent cell bodies are located in the peripheral nervous system of the cat. Circ Res. (1989) 64:55462. doi: 10.1161/01.RES.64.3.554

25. Perri V, Sacchi O, Casella C. Synaptically mediated potentials elicited by the stimulation of post-ganglionic trunks in the guinea-pig superior cervical ganglion. Pflugers Arch. (1970) 314:55-67. doi: 10.1007/BF00587046

26. Wallis D, Watson AH, Mo N. Cardiac neurones of autonomic ganglia. Microsc Res Tech. (1996) 35:6979. doi: 10.1002/(SICI)1097-0029(19960901)35:1andlt;69::AIDJEMT6andgt;3.0.CO;2-N

27. Bosnjak ZJ, Kampine JP. Intracellular recordings from the stellate ganglion of the cat. J Physiol. (1982) 324:273-83. doi: 10.1113/jphysiol.1982.sp014112

28. Bosnjak ZJ, Kampine JP. Electrophysiological and morphological characterization of neurons in stellate ganglion of cats. Am J Physiol. (1985) 248:R288-292. doi: 10.1152/ajpregu.1985.248.3.R288

29. Hoard JL, Hoover DB, Mabe AM, Blakely RD, Feng N, Paolocci N. Cholinergic neurons of mouse intrinsic cardiac ganglia contain noradrenergic enzymes, norepinephrine transporters, and the neurotrophin receptors tropomyosin-related kinase A and p75. Neuroscience. (2008) 156:12942. doi: 10.1016/j.neuroscience.2008.06.063

30. Kanazawa H, Ieda M, Kimura K, Arai T, Kawaguchi-Manabe H, Matsuhashi $\mathrm{T}$, et al. Heart failure causes cholinergic transdifferentiation of cardiac sympathetic nerves via gp130-signaling cytokines in rodents. J Clin Invest. (2010) 120:408-21. doi: 10.1172/JCI39778

31. Yang B, Slonimsky JD, Birren SJ. A rapid switch in sympathetic neurotransmitter release properties mediated by the p75 receptor. Nat Neurosci. (2002) 5:539-45. doi: 10.1038/nn0602-853

32. Coleridge JC, Kidd C, Sharp JA. The distribution, connexions and histology of baroreceptors in the pulmonary artery, with some observations on the sensory innervation of the ductus arteriosus. J Physiol. (1961) 156:591602. doi: 10.1113/jphysiol.1961.sp006695

33. Peterson DF, Brown AM. Pressor reflexes produced by stimulation of afferent fibers in the cardiac sympathetic nerves of the cat. Circ Res. (1971) 28:60510. doi: 10.1161/01.RES.28.6.605

34. Oldfield BJ, McLachlan EM. Localization of sensory neurons traversing the stellate ganglion of the cat. J Comp Neurol. (1978) 182:91522. doi: $10.1002 /$ cne. 901820509

35. Dale H. Pharmacology and nerve-endings (walter ernest dixon memorial lecture): (section of therapeutics and pharmacology). Proc R Soc Med. (1935) 28:319-32. doi: 10.1177/003591573502800330

36. Eccles JC, Fatt P, Koketsu K. Cholinergic and inhibitory synapses in a pathway from motor-axon collaterals to motoneurones. J Physiol. (1954) 126:52462. doi: 10.1113/jphysiol.1954.sp005226

37. Vaaga CE, Borisovska M, Westbrook GL. Dual-transmitter neurons: functional implications of co-release and co-transmission. Curr Opin Neurobiol. (2014) 29:25-32. doi: 10.1016/j.conb.2014.04.010

38. Jan LY, Jan YN. Peptidergic transmission in sympathetic ganglia of the frog. $J$ Physiol. (1982) 327:219-46. doi: 10.1113/jphysiol.1982.sp014228

39. Jan YN, Jan LY, Kuffler SW. A peptide as a possible transmitter in sympathetic ganglia of the frog. Proc Natl Acad Sci USA. (1979) 76:15015. doi: 10.1073/pnas.76.3.1501

40. Alston EN, Parrish DC, Hasan W, Tharp K, Pahlmeyer L, Habecker BA. Cardiac ischemia-reperfusion regulates sympathetic neuropeptide expression through gp130-dependent and independent mechanisms. Neuropeptides. (2011) 45:33-42. doi: 10.1016/j.npep.2010.10.002

41. Browning KN, Lees GM. Inhibitory effects of NPY on ganglionic transmission in myenteric neurones of the guinea-pig descending colon. Neurogastroenterol Motil. (2000) 12:33-41. doi: 10.1046/j.1365-2982.2000.00178.x

42. Burnstock G. Physiology and pathophysiology of purinergic neurotransmission. Physiol Rev. (2007) 87:659797. doi: 10.1152 /physrev.00043.2006

43. Pernow J, Schwieler J, Kahan T, Hjemdahl P, Oberle J, Wallin BG, et al. Influence of sympathetic discharge pattern on norepinephrine and neuropeptide Y release. Am J Physiol. (1989) 257:H866-872. doi: 10.1152/ajpheart.1989.257.3.H866

44. Verhaeghe RH, Vanhoutte PM, Shepherd JT. Inhibition of sympathetic neurotransmission in canine blood vessels by adenosine and adenine nucleotides. Circ Res. (1977) 40:208-15. doi: 10.1161/01.RES.40.2.208
45. Johnson MD. Synaptic glutamate release by postnatal rat serotonergic neurons in microculture. Neuron. (1994) 12:43342. doi: 10.1016/0896-6273(94)90283-6

46. Jonas P, Bischofberger J, Sandkuhler J. Corelease of two fast neurotransmitters at a central synapse. Science. (1998) 281:41924. doi: 10.1126/science.281.5375.419

47. Walker MC, Ruiz A, Kullmann DM. Monosynaptic GABAergic signaling from dentate to CA3 with a pharmacological and physiological profile typical of mossy fiber synapses. Neuron. (2001) 29:703-15. doi: 10.1016/S0896-6273(01)00245-8

48. Furshpan EJ, MacLeish PR, O'Lague PH, Potter DD. Chemical transmission between rat sympathetic neurons and cardiac myocytes developing in microcultures: evidence for cholinergic, adrenergic, and dual-function neurons. Proc Natl Acad Sci USA. (1976) 73:4225-9. doi: 10.1073/pnas.73.11.4225

49. Furshpan EJ, Landis SC, Matsumoto SG, Potter DD. Synaptic functions in rat sympathetic neurons in microcultures. I Secretion of norepinephrine and acetylcholine. J Neurosci. (1986) 6:1061-79. doi: 10.1523/JNEUROSCI.06-04-01061.1986

50. Potter DD, Landis SC, Matsumoto SG, Furshpan EJ. Synaptic functions in rat sympathetic neurons in microcultures. II Adrenergic/cholinergic dual status and plasticity. J Neurosci. (1986) 6:1080-98. doi: 10.1523/JNEUROSCI.06-04-01080.1986

51. Reichardt LF, Patterson PH. Neurotransmitter synthesis and uptake by isolated sympathetic neurones in microcultures. Nature. (1977) 270:14751. doi: $10.1038 / 270147 \mathrm{a} 0$

52. Schotzinger RJ, Landis SC. Cholinergic phenotype developed by noradrenergic sympathetic neurons after innervation of a novel cholinergic target in vivo. Nature. (1988) 335:637-9. doi: 10.1038/335637a0

53. Apostolova G, Dorn R, Ka S, Hallbook F, Lundeberg J, Liser $\mathrm{K}$, et al. Neurotransmitter phenotype-specific expression changes in developing sympathetic neurons. Mol Cell Neurosci. (2007) 35:397-408. doi: 10.1016/j.mcn.2007.03.014

54. Brodski C, Schaubmar A, Dechant G. Opposing functions of GDNF and NGF in the development of cholinergic and noradrenergic sympathetic neurons. Mol Cell Neurosci. (2002) 19:528-38. doi: 10.1006/mcne.2001.1093

55. Brodski C, Schnurch H, Dechant G. Neurotrophin-3 promotes the cholinergic differentiation of sympathetic neurons. Proc Natl Acad Sci USA. (2000) 97:9683-8. doi: 10.1073/pnas.160080697

56. Habecker BA, Pennica D, Landis SC. Cardiotrophin-1 is not the sweat gland-derived differentiation factor. Neuroreport. (1995) 7:41-4. doi: 10.1097/00001756-199512000-00009

57. Hiltunen PH, Airaksinen MS. Sympathetic cholinergic target innervation requires GDNF family receptor GFR alpha 2. Mol Cell Neurosci. (2004) 26:450-7. doi: 10.1016/j.mcn.2004.04.003

58. Rao MS, Patterson PH, Landis SC. Multiple cholinergic differentiation factors are present in footpad extracts: comparison with known cholinergic factors. Development. (1992) 116:731-44. doi: 10.1242/dev.116.3.731

59. Rao MS, Sun Y, Escary JL, Perreau J, Tresser S, Patterson PH, et al. Leukemia inhibitory factor mediates an injury response but not a target-directed developmental transmitter switch in sympathetic neurons. Neuron. (1993) 11:1175-85. doi: 10.1016/0896-6273(93)90229-K

60. Stanke M, Duong CV, Pape M, Geissen M, Burbach G, Deller T, et al. Targetdependent specification of the neurotransmitter phenotype: cholinergic differentiation of sympathetic neurons is mediated in vivo by gp 130 signaling. Development. (2006) 133:141-50. doi: 10.1242/dev.02189

61. Yamamori T, Fukada K, Aebersold R, Korsching S, Fann MJ, Patterson $\mathrm{PH}$. The cholinergic neuronal differentiation factor from heart cells is identical to leukemia inhibitory factor. Science. (1989) 246:14126. doi: $10.1126 /$ science. 2512641

62. Olivas A, Gardner RT, Wang L, Ripplinger CM, Woodward WR, Habecker BA. Myocardial infarction causes transient cholinergic transdifferentiation of cardiac sympathetic nerves via gp130. J Neurosci. (2016) 36:47988. doi: 10.1523/JNEUROSCI.3556-15.2016

63. Vega A, Luther JA, Birren SJ, Morales MA. Segregation of the classical transmitters norepinephrine and acetylcholine and the neuropeptide $\mathrm{Y}$ in sympathetic neurons: modulation by ciliary neurotrophic factor or prolonged growth in culture. Dev Neurobiol. (2010) 70:913-28. doi: 10.1002/dneu.20834 
64. Cifuentes F, Morales MA. Functional implications of neurotransmitter segregation. Front Neural Circuits. (2021) 15:738516. doi: 10.3389/fncir.2021.738516

65. Eccles JC. Chemical transmission and Dale’s principle. Prog Brain Res. (1986) 68:3-13. doi: 10.1016/S0079-6123(08)60227-7

66. Condon AF, Robinson BG, Asad N, Dore TM, Tian L, Williams JT. The residence of synaptically released dopamine on D2 autoreceptors. Cell Rep. (2021) 36:109465. doi: 10.1016/j.celrep.2021.109465

67. Tedjo W, Nejad JE, Feeny R, Yang L, Henry CS, Tobet S, et al. Electrochemical biosensor system using a CMOS microelectrode array provides high spatially and temporally resolved images. Biosens Bioelectron. (2018) 114:7888. doi: 10.1016/j.bios.2018.04.009

68. Tjahjono N, Jin Y, Hsu A, Roukes M, Tian L. Letting the little light of mind shine: Advances and future directions in neurochemical detection. Neurosci Res Nov. (2021) 2021:30. doi: 10.1016/j.neures.2021.11.012

69. Silm K, Yang J, Marcott PF, Asensio CS, Eriksen J, Guthrie DA. Synaptic vesicle recycling pathway determines neurotransmitter content and release properties. Neuron. (2019). 102:786-800 e785. doi: 10.1016/j.neuron.2019.03.031

70. Takacs VT, Cserep C, Schlingloff D, Posfai B, Szonyi A, Sos KE, et al. Cotransmission of acetylcholine and GABA regulates hippocampal states. Nat Commun. (2018) 9:2848. doi: 10.1038/s41467-018-05136-1

71. Fortin GM, Ducrot C, Giguere N, Kouwenhoven WM, Bourque MJ, Pacelli $\mathrm{C}$, et al. Segregation of dopamine and glutamate release sites in dopamine neuron axons: regulation by striatal target cells. FASEB J. (2019) 33:40017. doi: 10.1096/fj.201800713RR

72. Granger AJ, Wang W, Robertson K, El-Rifai M, Zanello AF, Bistrong $\mathrm{K}$, et al. Cortical ChAT $(+)$ neurons co-transmit acetylcholine and GABA in a target- and brain-region-specific manner. Elife. (2020) 9:57749. doi: 10.7554/eLife.57749.sa2
73. Liang K, Wei L, Chen L. Exocytosis, endocytosis, and their coupling in excitable cells. Front Mol Neurosci. (2017) 10:109. doi: 10.3389/fnmol.2017.00109

74. von Twickel A, Kowatschew D, Salturk M, Schauer M, Robertson B, Korsching $\mathrm{S}$, et al. Individual dopaminergic neurons of lamprey SNc/VTA project to both the striatum and optic tectum but restrict co-release of glutamate to striatum only. Curr Biol. (2019) 29:677-685 e676. doi: 10.1016/j.cub.2019.01.004

75. Ninomiya I, Malpas SC, Matsukawa K, Shindo T, Akiyama T. The amplitude of synchronized cardiac sympathetic nerve activity reflects the number of activated pre- and postganglionic fibers in anesthetized cats. J Auton Nerv Syst. (1993) 45:139-47. doi: 10.1016/0165-1838(93)90125-E

Conflict of Interest: The authors declare that the research was conducted in the absence of any commercial or financial relationships that could be construed as a potential conflict of interest.

Publisher's Note: All claims expressed in this article are solely those of the authors and do not necessarily represent those of their affiliated organizations, or those of the publisher, the editors and the reviewers. Any product that may be evaluated in this article, or claim that may be made by its manufacturer, is not guaranteed or endorsed by the publisher.

Copyright (C) 2022 Clyburn, Andresen, Ingram and Habecker. This is an open-access article distributed under the terms of the Creative Commons Attribution License (CC BY). The use, distribution or reproduction in other forums is permitted, provided the original author(s) and the copyright owner(s) are credited and that the original publication in this journal is cited, in accordance with accepted academic practice. No use, distribution or reproduction is permitted which does not comply with these terms. 